\title{
Simulation and Monitoring Brightness Temperature from LANDSAT TM Images in Urban Area
}

\author{
Fu Chen* and Jing Ma \\ Low Carbon Energy Institute \\ China University of Mining and Technology \\ Xuzhou 221008, China \\ *Corresponding author
}

\author{
Min Tan and Yuanwen Zeng \\ China University of Mining and Technology \\ Jiangsu Key Laboratory of Resource and Environmental \\ Information Engineering \\ Xuzhou 221008, China
}

\begin{abstract}
Brightness temperature (Tb), an effectively reflect the real surface temperature index, were quantitatively derived from LANDSAT TM images in Xuzhou city, China. Normalized difference vegetation index (NDVI) spatial model and normalized difference built-up index (NDBI) spatial model were also established in accordance with circular feature profiles using the technologies of RS and GIS. The results showed that: (1) there was a significantly negative correlation between NDVI and Tb, and a significantly positive correlation between NDBI and Tb, increasing of the correlation coefficient with the profile radius expanded; (2) The correlation between NDVI and Tb is greater than that between NDBI and $\mathrm{Tb}$, but the contribution of $\mathrm{Tb}$ to NDVI is less than NDBI; and (3) The relationship between NDBI and $\mathrm{Tb}$ was more affected by land use structures, more complicated land use structure makes the relationship between NDBI and Tb stronger. This study effectively reveals the correlation between Tb and NDBI or NDVI in spatial distribution, and has a good application prospective in urban planning and ecological construction planning.
\end{abstract}

Keywords-brightness temperature; normalized difference vegetation index; normalized difference built-up index; LANDSAT TM image

\section{INTRODUCTION}

Increasing urbanization usually gives rise to a dramatic change of the Earth's surface [1]. The urbanization process is substantially land cover transformation [2]. This alteration will inevitably result in the redistribution of incoming solar radiation, and induce the metropolitan area and its surrounding rural area contrast in surface radiance and air temperatures [3]. This phenomenon, known as Urban Heat Island (UHI), is a reflection of the totality of microclimatic changes brought about by man-made alterations of the urban surface [4]. The effect of UHI more and more intense and generates deeper and deeper influence on People's daily lives, so it get a lot of attention.

Many studies have been conducted primarily using NOAA AVHRR data and LANDSAT TM images in USA, Australia, Singapore and China to study the UHI effect in many cities [510]. The development of remote sensing technology provides a new means for the study of urban heat island effect; remote sensing image is utilized to inverse land surface temperature for exploring the space distribution rule of urban heat island [11]; and NDVI (Normalized Difference Vegetation Index) is introduced to characterize the coverage degree of vegetation in order to explore the relation between the coverage degree of vegetation and land surface temperature [12]. The 120-m spatial resolution LANASAT TM thermal infrared (TIR) data have also been utilized to derive surface temperature. Carnahan [5] and Larson [13] used TM TIR data to observe meso-scale temperature differences between the urban area and the rural area in Indianapolis, Indiana. Kim [14] studied the phenomenon of urban heat island in metropolitan Washington, D.C., and pinpointed the significance of soil albedo and moisture availability to surface energy balance. Nichol [8] carried out a detailed study using TM thermal data to monitor microclimate for housing estates in Singapore. Rajagopalan et al. [15] used A cloud-free LANDSAT image of Singapore to detect difference of temperature between the rural and the urban areas in the low tropics. Weng [16] examined the surface temperature pattern and its relationship with land cover in urban clusters in the Zhujiang Delta, China. More recently, researchers have used very high spatial resolution (10-m) ATLAS data (specifically, channel 13: 9.60 to $10.2 \mathrm{~mm}$ ) to assess the UHI effect during daytime and nighttime in several cities and found it effective [16-18].Normalized Difference Building Index (NDBI) proposed by Zha [19] provides new means for the study of urban heat island effect, and later the study of relation of NDBI and other character parameters and land surface temperature appear in succession [20-21]. The increasing availability of LANDSAT images and other satellite data provides opportunities to analyze UHI since the 1990s, whereas NDVI is often the only method for UHI data for the earlier decades. Only a few studies have been discussed the suitability index, particularly with respect to quantitative evaluation. Although NDVI can reflect vegetation coverage rather precisely, but lacking of the precision to characterize other land use type with NDVI. At the same time, NDBI is the parameter to characterize building land and causes errors in charactering other land use types inevitably. The accuracy of results will be reduced if different land use types in the whole study region are considered generally together. In this research, land use types in the study region are considered separately, we obtained NDVI from vegetation coverage land and NDBI from building land according to the surface parameters optimal relevance. The aims of this paper are (1) quantify spatial patterns of brightness temperature, (2) to examine the correlation between brightness temperature and NDVI or NDBI, and (3) to provide a valuable scheme for urban planning and ecological construction planning with the study area. 


\section{MATERIALS AND METHODS}

\section{A. Study Area}

The study area in this paper is Xuzhou City, which is located in the northwest part of Jiangsu province, China between $33^{\circ} 43^{\prime}-34^{\circ} 58^{\prime} \mathrm{N}, 116^{\circ} 22^{\prime}-118^{\circ} 40^{\prime} \mathrm{E}$. The local climate is warm temperate zone with humid maritime climate. The mean temperature is 19.6 degrees centigrade with annual rainfall ranging from 690 to $1130 \mathrm{~mm}$ and mostly distributed from July to October. It has an area of 11258 square $\mathrm{km}^{2}$ and with a population of 9.4 million. It has been the most important political, economic, and cultural centre in Jiangsu province, China. The Xuzhou municipality comprises four administrative districts in the proper and six rural counties. This study focuses on the city proper of Xuzhou, including Yunlong District, Gulou District, Quanshan District and part of Tongshan District (Figure I ).

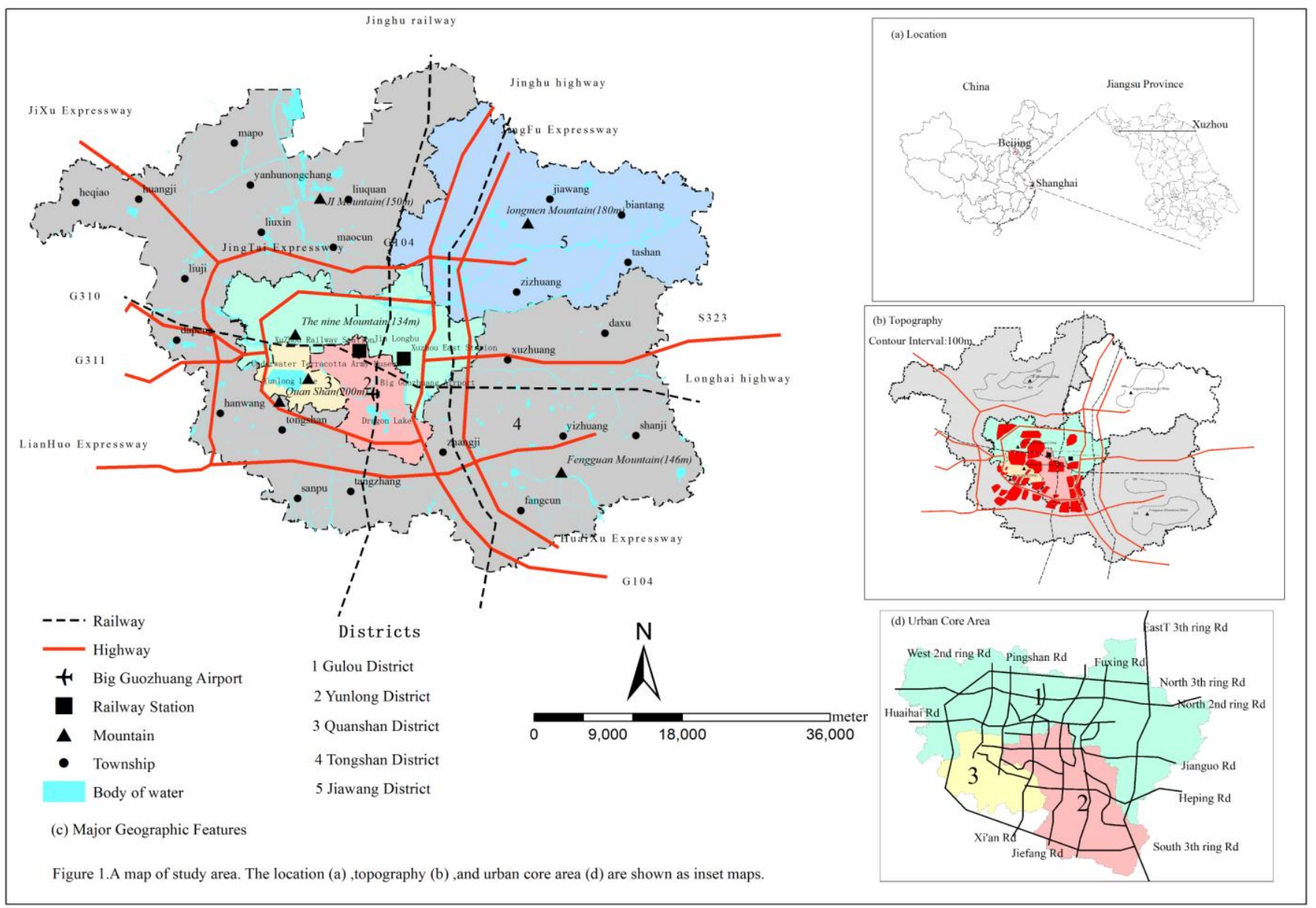

FIGURE I. A MAP OF STUDY AREA. THE LOCATION (A), TOPOGRAPHY (B), AND URBAN CORE (D) ARE SHOWN AS INSERT MAPS

\section{B. Data Pre-processing}

The data used in this study were three LANDSAT TM images, dated on 12 May 2005, 10 December 2008, and 1 August 2011, respectively. We use polynomial correction method for geometric correction. Firstly we select a number of corresponding points having obvious features as control points on the corrected images and the reference images which having geographical coordinates of the same region, respectively. Then we use geographical coordinates and image coordinates of these ground control points to calculate polynomial coefficients. Finally images will be corrected after we set each pixel coordinates of being corrected image to the polynomial, and each pixel can obtain the actual geographical coordinates. Each LANDSAT image was rectified to a common UTM coordinate system based on 1:50,000-scale topographic maps. The resultant root-mean-squared error was found to be 0.37 pixel ( $11.1 \mathrm{~m}$ on the ground) for the 2005 image, and 0.13 pixel ( $3.7 \mathrm{~m}$ on the ground) for the 2008 and the 2011 images.

\section{Land Cover Classification Method}

Based on International Biosphere-Geosphere Programme land classification system and combined with the real surface situation in urban area, The neural network (NN) implemented in this research is an interconnected group of natural or artificial neurons that uses a mathematical or computational model for information processing based on a connectionist approach to computation[22]. Geometric correction and projection transformation were conducted by ENVI 4.6 with UTM and WGS-84 as the projection coordinate system. The land covers are categorized 6 classes: (1) woodland, (2) 
grassland, (3) high-rise building, (4) low-rise building, (5)water, (6) wetland. The classification result is show in Figure II.

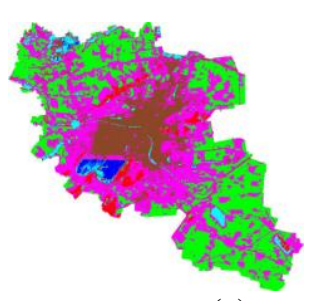

(a)

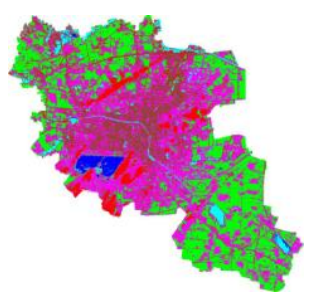

(b)

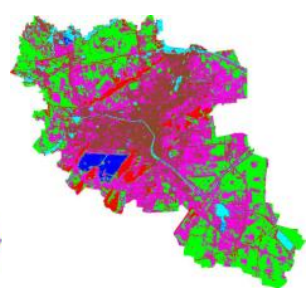

(c) high-rise building $\square$ low-rise building $\square$ woodland $\square$ grassland wetland $\square$ water body

FIGURE II. VARIOUS LAND COVERS OF 2005 (A), 2008 (B), AND 2011 (C) IN XUZHOU

\section{Inversion of Surface Brightness Temperature}

Surface radiant temperatures were derived from geometrically corrected TM thermal infrared data (band 6). According to the transferring characteristics of thermal infrared radiation in atmosphere and the receiving characteristics of LANDSAT TM data, the 6th wave bands were the most suitable for the calculation of land surface brightness temperature. So the 6th wave band was only selected for the calculation of brightness temperature to simplify workload and further analysis. A quadratic model was used to convert the digital number (DN) into radiant temperatures [23]:

$$
L_{b}=L_{\min }+\frac{L_{\max }-L_{\min }}{255} D N
$$

In the formula, $L_{\max }$ and $L_{\min }$ of LANDSAT 5 were $1.56 \mathrm{mw} \cdot \mathrm{cm}^{-2} \cdot \mathrm{sr}^{-1} \cdot u \mathrm{~m}^{-1}$ $0.1238 \mathrm{mw} \cdot \mathrm{cm}^{-2} \cdot s r^{-1} \cdot u m^{-1}$. So the formula was simplified as follows:

$$
L_{b}=0.1238+0.005632156 D N
$$

However, the temperature values obtained above are referenced to a black body. Therefore, corrections for emissivity (a) became necessary according to the nature of land cover. Vegetated areas were given a value of 0.95 and non-vegetated areas 0.92 [8]. The emissivity corrected surface temperatures were computed as follows [23]:

$$
T_{b}=\frac{K_{2}}{\ln \left(K_{1} / L_{b}+1\right)}
$$

In the formula, formula, T was brightness temperature, $K_{2}$ and $K_{l}$ were constants. As for $6^{\text {th }}$ wave band of LANDSAT 5,
$K_{1}=60.776 \mathrm{~mW} /\left(\mathrm{cm}^{2} \quad \bullet \quad \mathrm{sr} \quad \bullet \quad \mu_{\mathrm{m}}\right), \quad K_{2}=1260.56$ $\mathrm{mW} /\left(\mathrm{cm}^{2} \cdot \mathrm{sr} \cdot \mu_{\mathrm{m}}\right) ; L_{b}$ was thermal radiation intensity of the 6ith wave band. The distribution of brightness temperature in the study area is shown in Figure III.

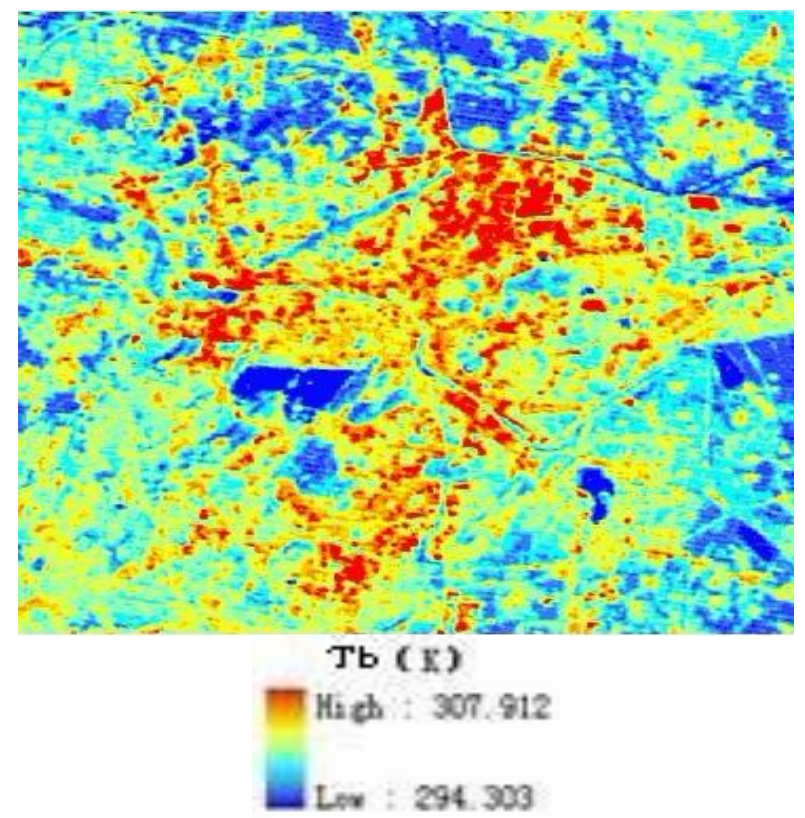

FIGURE III. SPATIAL DISTRIBUTION OF SURFACE BRIGHTNESS TEMPERATURE IN 2011.

\section{E. Computation of NDVI and NDBI}

NDVI (Normalized Difference Vegetation Index) is introduced to characterize the coverage degree of vegetation in order to explore the relation between the coverage degree of vegetation and land surface temperature. It is defined as follows [24]:

$$
\mathrm{N} \Delta \zeta \mathrm{I}=(\mathrm{TM} 4-\mathrm{TM} 3) /(\mathrm{TM} 4+\mathrm{TM} 3)
$$

NDBI (Normalized Difference Building Index) is introduced to characterize the coverage degree of building in order to explore the relation between the coverage degree of building and land surface temperature. It is defined as follows [19]:

$$
N D B I=(T M 5-T M 4) /(T M 5+T M 4)
$$

The NDVI and NDBI image were computed for 2005, 2008 and 2011 from visible $(0.63$ to $0.69 \mathrm{~mm})$ and near-infrared $(0.76$ to $0.90 \mathrm{~mm}$ ) data of TM images. The resultant NDVI and DVBI images were thresholded into two categories to represent vegetated and non-vegetated areas or construction and nonconstruction. Accordingly, the mean of diurnal brightness temperature of 12 May 2005, 10 December 2008, and 1 August 2011 in various land cover was calculated by ENVI 4.6, and data were statistically analyzed with Excel and SPSS 12.0 software. 


\section{F. Structuring of Characteristic Profiles}

A lot of circular characteristic profiles are uniformly selected with the center of study area being these circles' center, and the radius difference between adjacent profiles is $0.5 \mathrm{~km}$. Previous studies have used fractals as a spatial measure for describing and analyzing remotely sensed imagery with line profiles [3], but circular characteristic profiles were more suitable for the plain [21]. When structuring the characteristic profiles, first a value of 1 is assigned to the part of vegetation in the land use classification figure, and other land use types are assigned a value of 0 , so the vegetation distribution figure is extracted, then overlay analysis is carried out for NDVI figure, $\mathrm{Tb}$ distribution figure and the processed vegetation distribution figure. When profile data are extracted, the points whose value are zero in vegetation distribution figure are knocked out, thus NDVI in vegetation coverage land surface and corresponding $\mathrm{Tb}$ value are acquired. Construction land is treated in a similar way. FigureIV a shows the feature profiles on vegetation, Figure $\mathrm{IVb}$ shows the feature profiles on construction.

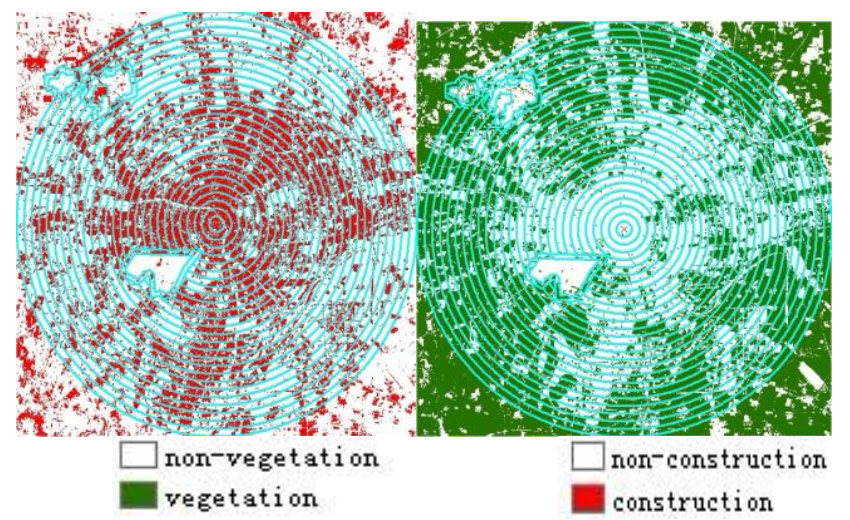

(a)

(b)

\section{RESULTS AND DISCUSSIONS}

\section{A. Spatial Patterns of Land Surface Brightness Temperature in Study Area}

The average values of brightness temperature by land cover type are summarized in Table 1. It is clear that brightness temperature in various land cover was highest in 1 August 2011, next came 12 May 2005, and 10 December 2008 was the lowest. The mean of brightness temperature in various land covers was as follows: high-rise building > low-rise building > woodland > grassland > wetland > water, But not all in accordance with the above rules. The brightness temperature in water was the lowest in seven kinds of land covers, while high-rise building trended to be higher, which was properly due to tight layout of high-rise building, poor ventilation and heat dispersion, or strong heat absorption of materials. Grassland had higher brightness temperature, but its area ratio was quite small, which was probably because grassland distributed in high-rise building and low-rise building dispersedly. In Figure 3 , the highest brightness temperature in 1 August 2011 is $307.912 \mathrm{~K}$ of high-rise building land and the lowest brightness temperature is $274.303 \mathrm{~K}$ of water bodies. Red area (high temperature area) mainly distribute in center of the city, because a large of intensive buildings exist in centre, the population density is relatively large, human activities are frequent, and more heat is generated. So that surface temperature in center region is higher than surrounding areas. The yellow area (middle temperature area) mainly distribute around the red area, this area is mainly low-rise building areas. The light blue areas (secondly low temperature) mainly distribute in suburb, agricultural land and urban-ruralintegration area, and the blue areas (low temperature area) mainly distribute in woodland and water bodies which are better in vegetation coverage.

FIGURE IV. CIRCULAR CHARACTERISTIC PROFILE ON VEGETATION (A) AND CONSTRUCTION(B).

TABLE I. AVERAGE SURFACE BRIGHTNESS TEMPERATURE $\left({ }^{\circ} \mathrm{C}\right)$ IN DIFFERENT LAND COVER TYPE.

\begin{tabular}{|c|c|c|c|c|c|c|c|c|c|c|}
\hline \multirow{2}{*}{ [1] Land Cover } & \multicolumn{3}{|c|}{ [2] 12 May 2005} & \multicolumn{3}{|c|}{ [3] 10 December 2008} & \multicolumn{4}{|c|}{ [4] 1 August 2011} \\
\hline & [5] & Mean [6] & Standard deviation & [7] & Mean [8] & Standard deviation & [9] & Mean & {$[10]$} & Standard deviation \\
\hline [11] Green space & [12] & 274.124 & [13] 3.331 & {$[14]$} & 268.757 & [15] 2.377 & {$[16]$} & 284.574 & & [17] 1.895 \\
\hline [18] High-rise Building & [19] & 281.342 & [20] 2.782 & {$[21]$} & 267.348 & [22] 2.459 & {$[23]$} & 292.751 & & [24] 2.278 \\
\hline [25] Low-rise Building & [26] & 278.784 & [27] 2.897 & {$[28]$} & 265.136 & [29] 1.971 & {$[30]$} & 291.458 & & {$[31] 2.068$} \\
\hline [32] Water & [33] & 272.124 & {$[34] 1.975$} & {$[35]$} & 264.584 & [36] 1.132 & [37] & 282.129 & & {$[38] 2.543$} \\
\hline [39] Wetland & [40] & 273.631 & [41] 2.133 & [42] & 269.451 & [43] 1.578 & [44] & 285.720 & & [45] 2.341 \\
\hline [46] Woodland & [47] & 275.247 & [48] 3.767 & [49] & 267.879 & {$[50] 2.345$} & {$[51]$} & 287.347 & & [52] 2.287 \\
\hline
\end{tabular}

\section{B. The Relationship between Surface Characteristic Parameters and $\mathrm{Tb}$}

As vegetation in first seven characteristic profiles are rare (Figure IVa), NDVI of vegetation land and the corresponding $\mathrm{Tb}$ value are extracted from the eighth profile whose radius is $4.0 \mathrm{~km}$. Due to the wide distribution of building land, NDBI of building land and the corresponding $\mathrm{Tb}$ value are extracted from the first profile whose radius is $0.5 \mathrm{~km}$, and the regression analysis is carried out on the extracted NDVI and Tb, NDBI and Tb separately. In Table 2 and Table 3, the results show that the Pearson coefficient between $\mathrm{Tb}$ and NDVI in all profiles are all negative number, while that between $\mathrm{Tb}$ and NDBI are all positive number. 
2015 International Conference on Environmental Engineering and Remote Sensing (EERS2015)

TABLE II. REGRESSIVE RELATIONSHIP BETWEEN SURFACE BRIGHTNESS TEMPERATURE AND NDVI

\begin{tabular}{|c|c|c|c|c|c|}
\hline Profile $\operatorname{radius}(\mathrm{km})$ & Pearson coefficient & Regression equation & Profile $\operatorname{radius}(\mathbf{k m})$ & Pearson coefficient & Regression equation \\
\hline 4.0 & $-0.383^{* *}$ & $Y=-5.657 X+300.609$ & 9.0 & $-0.551^{* *}$ & $Y=-5.774 X+301.238$ \\
\hline 4.5 & $-0.268^{* *}$ & $Y=-4.288 X+300.586$ & 9.5 & $-0.577^{* *}$ & $Y=-6.528 X+301.529$ \\
\hline 5.0 & $-0.398^{* *}$ & $Y=-6.026 X+301.114$ & 10.0 & $-0.545^{* *}$ & $Y=-6.759 X+301.186$ \\
\hline 5.5 & $-0.358^{* *}$ & $Y=-4.332 X+300.649$ & 10.5 & $-0.584^{* *}$ & $Y=-7.341 X+301.443$ \\
\hline 6.0 & $-0.471^{* *}$ & $Y=-4.505 X+300.929$ & 11.0 & $-0.636^{* *}$ & $Y=-7.570 X+301.503$ \\
\hline 6.5 & $-0.463^{* *}$ & $Y=-6.570 X+301.346$ & 11.5 & $-0.525^{* *}$ & $Y=-6.178 X+301.060$ \\
\hline 7.0 & $-0.485^{* *}$ & $Y=-7.073 X+301.550$ & 12.0 & $-0.589^{* *}$ & $Y=-7.824 X+301.581$ \\
\hline 7.5 & $-0.48^{* *}$ & $Y=-7.147 X+301.503$ & 12.5 & $-0.652^{* *}$ & $Y=-6.981 X+301.645$ \\
\hline 8.0 & $-0.476^{* *}$ & $Y=-5.767 X+300.948$ & 13.0 & $-0.524^{* *}$ & $Y=-6.093 X+300.986$ \\
\hline 8.5 & $-0.571^{* *}$ & $Y=-6.882 X+301.746$ & 13.5 & $-0.572^{* *}$ & $Y=-6.667 X+301.239$ \\
\hline
\end{tabular}

TABLE III. REGRESSIVE RELATIONSHIP BETWEEN SURFACE BRIGHTNESS TEMPERATURE AND NDBI

\begin{tabular}{|c|c|c|c|c|c|}
\hline Profile $\operatorname{radius}(\mathbf{k m})$ & Pearson coefficient & Regression equation & $\begin{array}{c}\text { Profile } \\
\text { Radius }(k m)\end{array}$ & Pearson coefficient & Regression equation \\
\hline 0.5 & $0.141^{* *}$ & $Y=7.130 X+300.587$ & 7.5 & $0.347^{* *}$ & $Y=7.378 X+299.888$ \\
\hline 1.0 & $0.141^{* *}$ & $Y=6.316 X+300.588$ & 8.0 & $0.471^{* *}$ & $Y=7.175 X+299.467$ \\
\hline 1.5 & $0.220^{* *}$ & $Y=5.599 X+300.118$ & 8.5 & $0.368^{* *}$ & $Y=7.224 X+299.658$ \\
\hline 2.0 & $0.214^{* *}$ & $Y=6.045 X+300.254$ & 9.0 & $0.330^{* *}$ & $Y=6.622 X+299.962$ \\
\hline 2.5 & $0.309^{* *}$ & $Y=5.970 X+299.935$ & 9.5 & $0.364^{* *}$ & $Y=7.179 X+299.563$ \\
\hline 3.0 & $0.309^{* *}$ & $Y=5.970 X+299.935$ & 10.0 & $0.396^{* *}$ & $Y=7.460 X+299.320$ \\
\hline 3.5 & $0.163^{* *}$ & $Y=7.111 X+300.559$ & 10.5 & $0.516^{* *}$ & $Y=8.078 X+299.218$ \\
\hline 4.0 & $0.371^{* *}$ & $Y=7.242 X+299.747$ & 11.0 & $0.437^{* *}$ & $Y=8.086 X+299.074$ \\
\hline 4.5 & $0.250^{* *}$ & $Y=6.173 X+300.182$ & 11.5 & $0.504^{* *}$ & $Y=8.659 X+299.194$ \\
\hline 5.0 & $0.333^{* *}$ & $Y=6.477 X+300.176$ & 12.0 & $0.353^{* *}$ & $Y=7.257 X+299.454$ \\
\hline 5.5 & $0.255^{* *}$ & $Y=5.900 X+300.563$ & 12.5 & $0.348^{* *}$ & $Y=7.574 X+299.379$ \\
\hline 6.0 & $0.449^{* *}$ & $Y=7.604 X+299.399$ & 13.0 & $0.289^{* *}$ & $Y=7.713 X+299.061$ \\
\hline 6.5 & $0.341^{* *}$ & $Y=7.574 X+299.742$ & 13.5 & $0.272^{* *}$ & $Y=7.567 X+299.411$ \\
\hline 7.0 & $0.481^{* *}$ & $Y=7.857 X+299.705$ & & & \\
\hline
\end{tabular}

Previous studies have confirmed that the correlation between $\mathrm{Tb}$ and NDVI or NDBI existed [3, 16-20], but the correlation coefficient in each profile is different, which verifies that the correlation of $\mathrm{Tb}$ and NDVI and the correlation of $\mathrm{Tb}$ and NDBI have differences in space. In Figure $\mathrm{V}$ we found out the Pearson coefficient increases with the increasing of the profile radius, and the correlation coefficient of $\mathrm{Tb}$ and NDVI or NDBI upward trend from center to edge of urban with the diversification of land cover (Figure VIa, VIb). However, with the increasing of the profile radius, the increase of NDBI was mainly due to scope of change. As buildings in center are comparative intensive, NDBI is high, so no matter how $\mathrm{Tb}$ changes NDBI is fluctuated in a definite scope; while the edge profile is influenced by non-construction land, fluctuation range of NDBI value is large, so that the Pearson coefficient is higher than the center profile. Besides, as the pixel number in center profile is possibly less than that in edge profile, exceptional value influences regression relation largely [1,3], so that the Pearson coefficient is small. The influence of exceptional value of NDVI takes the main part duo to line profile methods [21]. We adopt the circular profile method can effectively reduce the influence of land cover diversity. This method is only used in Xuzhou city, more research is needed to verify its correctness in future.

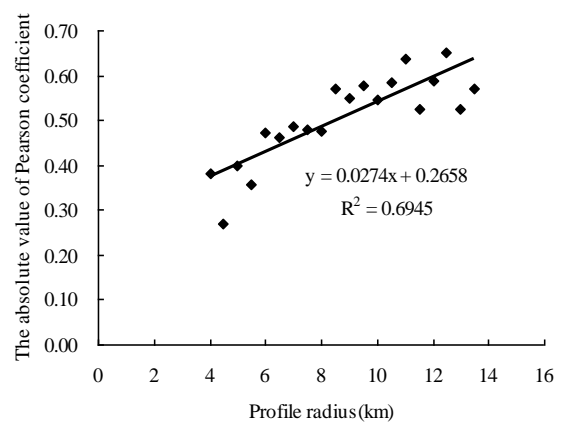

FIGURE V. CHANGES PEARSON COEFFICIENTS WITH PROFILES RADIUS 

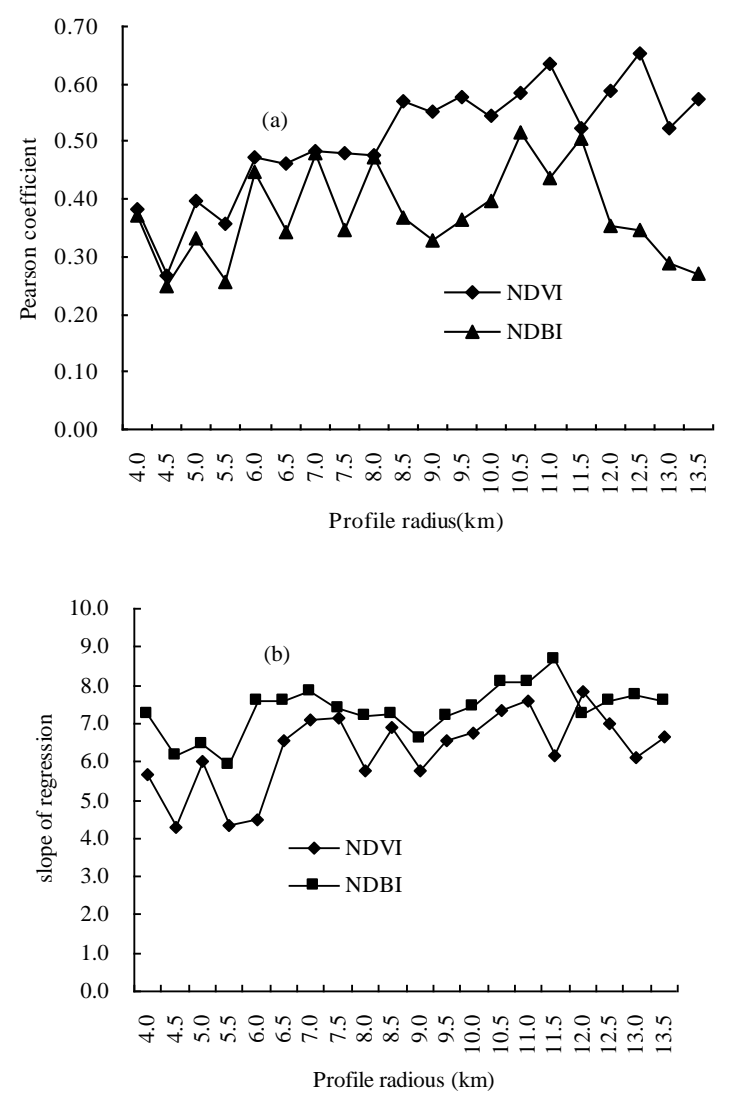

FIGURE VI. COMPARISON OF PEARSON COEFFICIENT (A) AND SLOP OF REGRESSION EQUATION (B)

\section{Effect of Land Cover on Surface Brightness Temperature}

The surface brightness temperature of various land covers shows different changes (Table 1). Water bodies have the steadiest change of brightness temperature, and also has better cooling effects, while grassland or construction land have the most unsteady change of brightness temperature, and also has stronger temperature raising and maintaining. We have chosen Yunlong Lake (about $5.80 \mathrm{~km} 2$ ) and its surrounding area as a research object, different brightness temperature value is used to carry out three-dimensional simulation for the surroundings of Yunlong Lake (Figure VI). It is obviously that the high temperature area represents an island in 3D simulation map, while Yunlong Lake looks like a pit. At the same time, we found that the brightness temperature of the surrounding of Yunlong Lake not rise abruptly but gradually increased, which illustrates that Yunlong Lake has cooling effect on its surroundings in a certain range. To verify the influence scope, 13 profiles are made in the north bank of Yunlong Lake in a regular of $30 \mathrm{~m}$ intervals. We had chosen the north bank of Yunlong Lake, because its single land cover can eliminate the adverse effect. In Figure VII the influence radius of Yunlong Lake on the surroundings is about $300 \mathrm{~m}$, three hundred meters outside the area without any effect. The effects of areas and shape of water body on surface brightness temperature have not taken into account because of not enough samples in this paper (Figure VIII). Previous studies have never considered the effect of water bodies on the land surface brightness temperature, which greatly reduced the accuracy of the research. Therefore, in our studies, we have removed the effect of water bodies based on the above conclusions.

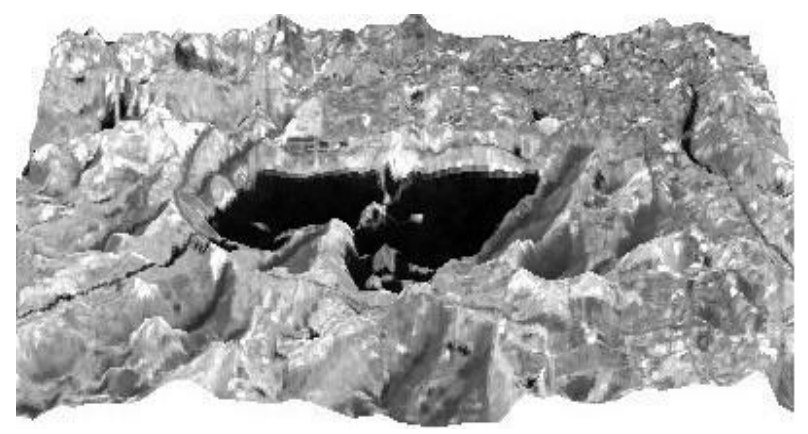

FIGURE VII. 3D SIMULATION MAP OF BRIGHTNESS TEMPERATURE AROUND YULONG LAKE.

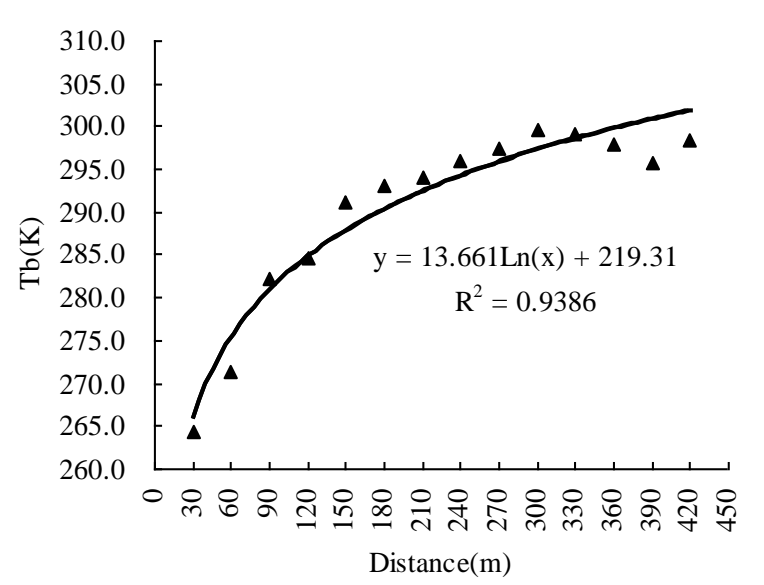

FIGURE VIII. CHANGES OF SURFACE BRIGHTNESS TEMPERATURE WITH DISTANCE

Many factors, such as solar illumination, vegetation state, atmospheric effect, land cover pattern, and topography, affect the fractal dimensionality from LANDSAT TM images. More research is needed to differentiate the impact of each element [3]. Hyperspectral remote sensing data may be desirable to relate urban topography to studies of surface brightness temperature [8]. Although the effects of surface characteristic parameters on surface temperature have been taken into account in this paper, but surface characteristic parameters are very complex. Several authors suggest scrutinizing the temperatures of each part of land use system and examining the effects of different cover structures, such as landscape characteristics, surface roughness, atmospheric effects, and soil moisture [17-20]. The essence of city makes life better and need to pay more attention to environmental problems in the future.

\section{CONCLUSION}

The utility of LANDSAT TM images to identify the potential causes of the effect of various land covers on the land surface brightness temperature was explored to how the urban environment can be improved by optimizing land cover pattern. 
The main results and advancement of the present research are the following.

( i ) The utility of LANDSAT TM images to detect the land surface brightness temperature in Xuzhou city have proved to be effective. The surface brightness temperature of urban area is obviously higher than that of suburb, and the sequence of the average brightness temperature from high to low is high-rise building, low-rise building, grassland, woodland, wetland, and water body.

(ii) The effect of various land covers on surface brightness temperature is significant difference. Water has cooling effect on its surroundings and the effect $\mathrm{s}$ gradually reduced with the distance. The influence radius of water body on surface brightness temperature, like Yunlong Lake (about $5.80 \mathrm{~km} 2$ ), is around $300 \mathrm{~m}$.

(iii) The results show that NDVI and Tb represent negative correlation, while NDBI and Tb represent positive correlation, and the correlation coefficient increases with the profile radius expanded. Comparison between NDVI and NDBI, the former is higher than the latter in the correlation with $\mathrm{Tb}$, but on the contribution to $\mathrm{Tb}$, the latter is far higher than the former.

\section{ACKNOWLEDGMENT}

The authors acknowledge the support of Project supported by the Key Projects in the National Science \& Technology Pillar Program during the Twelfth Five-year Plan Period (2012BAB11B06) and the Priority Academic Program Development of Jiangsu Higher Education Institutions (PAPD).

\section{REFERENCES}

[1] J.H. PAN, W.C. HAN. Urban expansion and its heat island response in Lanzhou City based on remote sensing analysis. Chinese J. Ecology. 30(2011) 2597-2603

[2] MORRIS C J G, SIMMONDS I, PLUMMER N. Quantification of the influences of wind and cloud on the nocturnal urban heat island of a large city[J]. Journal of Applied Meteorology articles, 2001, 40(2):169182.

[3] Q.H. Weng. A remote sensing-GIS evaluation of urban expansion and its impact on surface temperature in the Zhujiang Delta, China. International J. Remote Sensing. 22(2001) 1999-2014

[4] H.E. Landsberg. The Urban Climate. Academic Press (1981) New York p14

[5] W.H. Carnahan, R.C. Larson. An analysis of an urban heat sink. Remote Sensing Environment. 33(1990) 65-71

[6] K.P Gallo, A.L. McNab, T.R. Karl, J.F. Brown, J.J. Hood, J.D. Tarpley. The use of NOAA AVHRR data for assessment of the urban heat island effect. J. Applied Meteorology. 32(1993) 899-908

[7] D.E Gibbons, G.E. Wukelic. Application of LANDSAT Thematic Mapper data for coastal thermal plum analysis at Diablo Canyon. Photogrammetric Engineering Remote Sensing. 55(1989) 903-909

[8] J.E. Nichol. A GIS-based approach to microclimate monitoring in Singapore's high-rise housing estates. Photogrammetric Engineering Remote Sensing. 60(1994) 1225-1232

[9] M. Roth, T.R. Oke, W.J. Emery. Satellite derived urban heat islands from three coastal cities and the utilisation of such data in urban climatology. International J. Remote Sensing. 10(1989) 1699-1720

[10] C.P. Tso. A survey of urban heat island studies in two tropical cities. Atmospheric Environment. 30(1996) 507-519

[11] Q.H. Weng. Fractal analysis of satellite-detected urban heat island effect. Photogram Metric Engineering Remote Sensing. 69(2003) 555-566

[12] C. P. Lo. D. A. Quattrochi. J. C. Luvall. Application of high-resolution thermal infrared remote sensing and GIS to assess the urban heat island effect. International J. Remote Sensing. 18(1997) 287-303

[13] R.C. Larson, W.H. Carnahan. The influence of surface characteristics on urban radiant temperatures. Geocarto International. 12(1997) 5-16

[14] H.H. Kim. Urban heat island. International J. emote Sensing. 13(1992) 2319-2336

[15] P. Rajagopalan, N.H. Wong, K.W. D. Cheong. Microclimatic modeling of the urban thermal environment of Singapore to mitigate urban heat island. Solar Energy. 82(2008) 727-745

[16] J.A. Scbrino, J.C. Jimenez, L. Paolino. Land surface temperature retrieval from LANDSAT TM5. Remote Sensing Environment. 90(2004) 434-440

[17] D.A. Quattrochi, N.S. Goel. Spatial and temporal scaling of thermal remote sensing data. Remote Sensing Review. 12(1995) 255-286

[18] D.A. Quattrochi, M.K. Ridd. Measurement and analysis of thermal energy responses from discrete urban surfaces using remote sensing data. International J. Remote Sensing. 15(1994) 1991-2022

[19] Y. Zha, S. X. NI, S. Yang. An Effective Approach to Automatically Extract Urban Land-use from TM lmagery. Chinese J. Remote Sensing. 7(2003) 37-40

[20] P. F. WU, M. J. Wang, X.X. Zhang. Distribution of urban heat island effects based on normalized difference built-up index in Beijing city. Ecology Environmental Sciences. 18(2009) 1325-1331

[21] Y. W. Zeng, F. Chen, W. C. Wang. The relationship between land surface brightness temperature and surface characteristic parameters in single land use type. Agricultural Science in Jiangsu. 40(2012) 317-320

[22] F. Chen, N. Wei, H. B. Yang, Q. Tang, L. Wang. The changes of land use and cover and NPP in mining area: A case study in China. Proceedings-2011 19th International Conference on Geoinformatics (2011) Elsevier 327-343

[23] E. Malaret, L.A. Bartolucci, D.F. Lozano, P.E. Anuta, C.D. McGillem. LANDSAT-4 and LANDSAT-5 Thematic Mapper data quality analysis. Photogrammetric Engineering Remote. 51(1985) 1407-1416

[24] D.A. Artis, W.H. Carnahan. Survey of emissivity variability in thermography of urban areas. Remote Sensing Environment. 12(1982) 313-329J. Clerk Maxwell, A Treatise on Electricity and Magnetism, 3rd ed., vol. 2. Oxford: Clarendon, 1892, pp.68-73. 